IZA DP No. 9065

The Inheritance of Educational Inequality among Young People in Developing Countries

Francesco Pastore

Federica Roccisano

May 2015 


\title{
The Inheritance of Educational Inequality among Young People in Developing Countries
}

\author{
Francesco Pastore \\ Seconda Università di Napoli, \\ IZA, AIEL and AISSEC \\ Federica Roccisano \\ Catholic University of Milan (Piacenza), \\ MEDAlics and University for Foreigners of Reggio Calabria
}

Discussion Paper No. 9065

May 2015

IZA
P.O. Box 7240
53072 Bonn
Germany

Phone: +49-228-3894-0

Fax: +49-228-3894-180

E-mail: iza@iza.org

Any opinions expressed here are those of the author(s) and not those of IZA. Research published in this series may include views on policy, but the institute itself takes no institutional policy positions. The IZA research network is committed to the IZA Guiding Principles of Research Integrity.

The Institute for the Study of Labor (IZA) in Bonn is a local and virtual international research center and a place of communication between science, politics and business. IZA is an independent nonprofit organization supported by Deutsche Post Foundation. The center is associated with the University of Bonn and offers a stimulating research environment through its international network, workshops and conferences, data service, project support, research visits and doctoral program. IZA engages in (i) original and internationally competitive research in all fields of labor economics, (ii) development of policy concepts, and (iii) dissemination of research results and concepts to the interested public.

IZA Discussion Papers often represent preliminary work and are circulated to encourage discussion. Citation of such a paper should account for its provisional character. A revised version may be available directly from the author. 
IZA Discussion Paper No. 9065

May 2015

\section{ABSTRACT}

\section{The Inheritance of Educational Inequality among Young People in Developing Countries}

This letter provides new evidence on the extent of the inheritance of educational inequality in the eight developing countries (Azerbaijan, China, Egypt, Iran, Kosovo, Mongolia, Nepal, Syria) where the ILO carried out the first wave of School-to-Work Transition survey. We observe different patterns of correlation between the level of intergenerational mobility, the educational upgrade and the role of parents' in sons' and daughters' education.

JEL Classification: D63, H52, I24, P46, P52

Keywords: intergenerational mobility, educational persistence, developing economies

Corresponding author:

Francesco Pastore

Department of Law

Seconda Università di Napoli

Palazzo Melzi, Piazza Matteotti

I-81055, Santa Maria Capua Vetere (Caserta)

Italy

E-mail: francesco.pastore@unina2.it 


\section{Introduction}

A new strand of research is aiming to assess the size and determinants of the intergenerational transfer of human capital and poverty in both developed and developing countries. The findings of this paper are novel to the literature for two main reasons. First, the evidence on developing countries is meagre. In their study of 42 countries of all continents, Hertz et al. (2007) do not include Mongolia, Azerbaijan, Syria, Iran, Kosovo and China ${ }^{1}$. Second, the data used focus especially on the youngest generation (mainly 15-29 years old) ${ }^{2}$, which allows us catching the most recent trends and to cover a group which has been neglected until now.

The letter has a simple and standard structure. After motivating the research and shortly discussing methodology and data, we present the findings and some summary remarks.

\section{Motivation}

During the last seventy years, the education attainment level of the population in developed as well as in emerging economies has dramatically increased. As Hertz (2007) and Chusseau and Hellier (2012) recently confirmed, the intergenerational transmission of education is an important tool to assess the extent of intergenerational mobility in a society. Particularly in emerging economies, understanding the intergenerational transmission of education is important to comprehend the genesis of the so-called under education traps. This is the situation where certain families (because of the neighbourhood effects, the fixed costs of education or a problem in the educational system) remain uneducated from one generation to the next (Aziaradis and Stachurski, 2005). In addition, the transmission of education is a good proxy for the future degree of intergenerational mobility. While many studies prefer to consider the level of income, the transmission of education is a much more reliable variable for it has an important feature: different from income that can change significantly during the lifecycle of an individual, the level of education is generally constant. Of course, also this measure has its own shortcomings, such as the measurement errors induced by ever more frequent educational reforms and requirements from the demand side.

\footnotetext{
${ }^{1}$ About China, Hertz et al. have used data of Rural China presents in the World Bank-sponsored Living Standards Measurement Surveys.

${ }^{2}$ For some countries, age groups are slightly different.
} 


\section{Methodology}

The standard Solon (1992) equation measures intergenerational mobility by comparing the income (and socio-economic status) of parents and that of their sons:

$$
y_{i 1}^{c}=\alpha^{c}+\beta_{y}^{c} y_{i 0}^{c}+\varepsilon_{c i}
$$

where $y_{i 0}^{c}$ is the vector of the parents' permanent incomes, and $y_{i 1}^{c}$ is the vector of children' permanent incomes. Intergenerational mobility is proxied by $\beta$, the intergenerational elasticity of income. But as Hertz et al. have underlined there are some limitations in considering only the regression of the log income. That is why we need to connect income and education.

To regress the information about parents, we use a Mincerian equation in which the log income of parents is a function of $\alpha$, the level of education, and $\mathrm{p}_{0}$ is the percentage change in income generated by an extra year of education:

$$
y_{0}=\alpha_{0}+p_{0} h_{0}+u_{0}
$$

For the regression of child's information we will consider their personal level of education $\left(\mathrm{h}_{1}\right)$ and the effect of parental education $\left(\mathrm{h}_{0}\right)$,:

$$
y_{1}=\alpha_{1}+p_{1} h_{1}+\lambda h_{0}+\delta y_{0}+u_{1}
$$

To overcome the problems generated by the two regression error terms $\left(\mathrm{u}_{0}\right.$ and $\left.\mathrm{u}_{1}\right)$, and to capture the covariance between $\mathrm{u}_{0}$ and the child's personal level of education, Hertz et al. generate a final parameter:

$$
\phi=\operatorname{Cov}\left(h_{1} u_{0}\right) / \operatorname{Var}\left(u_{0}\right)
$$

Which can be interpreted as the effect of the part of parental income that is uncorrelated to their own education, but which is correlated with their children' education. By these premises, the relation between the traditional $\beta$, the intergenerational income elasticity, and the new $\beta_{h}$ measured considering the regression of education of parents, is:

$$
\beta_{h}=\delta+\frac{\left(p_{1} \beta_{h}+\lambda\right)}{p_{0}} R^{2}+p_{1} \phi\left(1-R^{2}\right)
$$

where $R^{2}$ will be the correlation coefficient that measures the value of the variance explained in the parents' income equation.

\section{Data}

The econometric analysis is based on 8 School-to-Work Transition Surveys (Azerbaijan, China, Egypt, Iran, Kosovo, Mongolia, Nepal and Syria) carried out by the ILO together with national statistical offices over the years from 2004 to 2006. The sample size ranges between 1336 young people (Kosovo) and 6,633 (China). Only three of the surveys (Azerbaijan, Egypt 
and Mongolia) are nationally representative. The Chinese survey covers four urban areas (Dalian, Changsha, Liuzhou and Tianjin); the Iranian survey covers three provinces (East Azarbayejan, Lorestan and Tehran); the Kosovan survey covers five out of seven regions (Pristina, Mitrovica, Gijlan, Gjakova, Prizren); the Nepalese survey covers three areas (Banke, Kathmandu Valley - including Bhaktapur, Kathmandu and Lalitpur districts - and Morang); and, finally, the Syrian survey covers five provinces (Aleppo, Damascus (urban and rural), Hamah and Tartus).

Three specific age groups may be identified: the "teenagers", aged 15-19 years; the "young adults”, aged 20-24 years; and those aged 24-29 years ${ }^{3}$. We exclude from the analysis the individuals still in education, but we cannot avoid a certain underestimation of intergenerational mobility among the youngest age segment, since the most skilled are still in education.

\section{Findings}

Figure 1 provides the first available estimates of the intergenerational educational regression coefficients and correlations by year of birth in the aforementioned countries. As outlined in the methodology section, these two indices are obtained from running a series of regressions of the education of children as a function of the education of their parents. The estimated coefficient of parents' education is a measure of grade persistence, whereas the square root of the $\mathrm{R}^{2}$ of the estimated equation is the correlation coefficient, a measure for standardized persistence. More important are the values relative to non-students of at least 24 years old (born in 1983 or earlier), when everybody has finished her studies, or also 20 years old (born in 1986 or earlier), as suggested in the relevant literature (Haider and Solon, 2006). Each panel also reports the world averages of $\beta$ and $r$ estimated in Hertz et al. on prime-age workers as a reference. Finally, to investigate the trend of intergenerational mobility across gender, we report also the value of $\beta$ and $r$ for sons and daughters.

Figure 1 shows four patterns The first trend refers to the case of Egypt and Mongolia (panels 1 and 2) in which, for sons born before 1982, the $\beta$ are higher than the world average, while decreasing after 1982; $r$ follows a similar trend. The second case is that of China and Nepal (panels 3 and 4), where the national level of $\beta$ is lower than the world average, while the national level of $r$ is higher than the world average. Iran and Syria (panels 5 and 6) register a decreasing level of both $\beta$ and $r$ after the early 1980s. Finally, Azerbaijan and Kosovo's (panels 7 and 8) $\beta$ and $r$ are lower than the world average.

\footnotetext{
${ }^{3}$ No information is available on the latter age group in the case of Syria. For further information on the SWT survey, see: http://www.ilo.org/employment/areas/WCMS_159352/lang--en/index.htm.
} 
The Figure reports also gender differences. In Egypt and Mongolia, the coefficients relative to men are higher than those of women: an upgrade in the economic condition could be a strong contributing factor to improved educational attainment for women (Huang, 2013). While in China the influence of parental background is much more present for women ${ }^{4}$. In the other countries there are no apparent gender differences.

\section{[Figure 1]}

This trend of $\beta$ and $r$ means that the level of mobility between sons and their parents is going down: sons could live differently from their parents. But this difference could be an upgrade or a downgrade of sons' with respect to their parents' condition. In figure 2 we make a comparison between the years of education of sons measured on the years of education of their parents and the level of $\beta$ and $r$ for the over 24 years old (over 20 for Kosovo and Syria).

\section{[Figure 2]}

The previous patterns are confirmed. Mongolia and China have a low upgrade of education between sons and parents and a high rate of $\beta$, while Nepal, Syria and Iran have a lower rate of $\beta$ and a good trend of education. Egypt and Kosovo are in two opposite positions: the first with very high levels of both the rate of education and the rate of $\beta$, and the second with lower levels of the two indicators. If we consider also the level of $r$, as the influence of parents' income in sons' condition, we can see how Egypt and Syria have low level of $\beta$, while Mongolia, China, Nepal present a better level of sons' education, but a higher level of $\beta^{5}$. Finally, in countries that have recently faced an exogenous shock (war or economic crises), like Kosovo or Azerbajian, we register a lower upgrade of the education level and also a lower rate of $\beta$.

\section{Concluding remarks}

Our analysis provides new evidence of the intergenerational transmission of education on a number of developing countries. We find different kinds of correlation between the upgrade of the educational level from parents to son, the measurement of intergenerational mobility and the influence of parents' income in sons' education. Some cases of extreme intergenerational mobility (Egypt and Syria) could hint at the recent turmoil experienced in these countries.

\footnotetext{
${ }^{4}$ The intergenerational mobility level is rigid in South Asia because of the role of parents' impact on fertility choices, household division of labor between men and women, and women's participation in the labor market (Grossjean, Khattar, 2014)

${ }^{5}$ A recent study on China shows that urban China is one of the least socially mobile places in the world in terms of intergenerational mobility of incomes (Gong et al., 2012).
} 


\section{References}

Azariadis, C. and J. Stachurski (2005), "Poverty Traps” in P. Aghion and S. Durlauf (eds.), Handbook of Economic Growth, Elsevier, North Holland.

Chusseau, N. and J. Hellier (2012), "Education, intergenerational mobility and inequality”, in: J. Hellier and N. Chusseau Eds, Growing Income Inequalities, Economic Analyses, Palgrave MacMillan, 227-273.

Gong, C. H., Leigh, A. and Meng, X. (2012) Intergenerational Income Mobility in Urban China, Review of Income and Wealth, 58, $481-503$.

Grosjean, P. and R. Khattar (2014). It's raining men! Hallelujah? Australian School of Business Research Paper No. 2014 ECON 29.

Haider, S.J. and Solon, G. 2006. Life-Cycle Variation in the Association between Current and Lifetime Earnings, American Economic Review, 96(4): 1308-1320.

Hertz, T., T. Jayasundera, P. Piraino, S. Selcuk, N. Smith, e A. Verashchagina (2007) "The Inheritance of Educational Inequality: International Comparisons and Fifty-Year Trends," The B.E. Journal of Economic Analysis \& Policy: 7(2: Advances): Article 10.

Huang J., (2013) Intergenerational Transmission of Educational Attainment: The Role of Household Assets, Economics of Education Review, v33 p112-123

Solon, G. (1992), "Intergenerational Income Mobility in the United States", American Economic Review, 82(3): 393-408. 


\section{Appendix}

Figure 1: Intergenerational educational regression coefficients and correlations
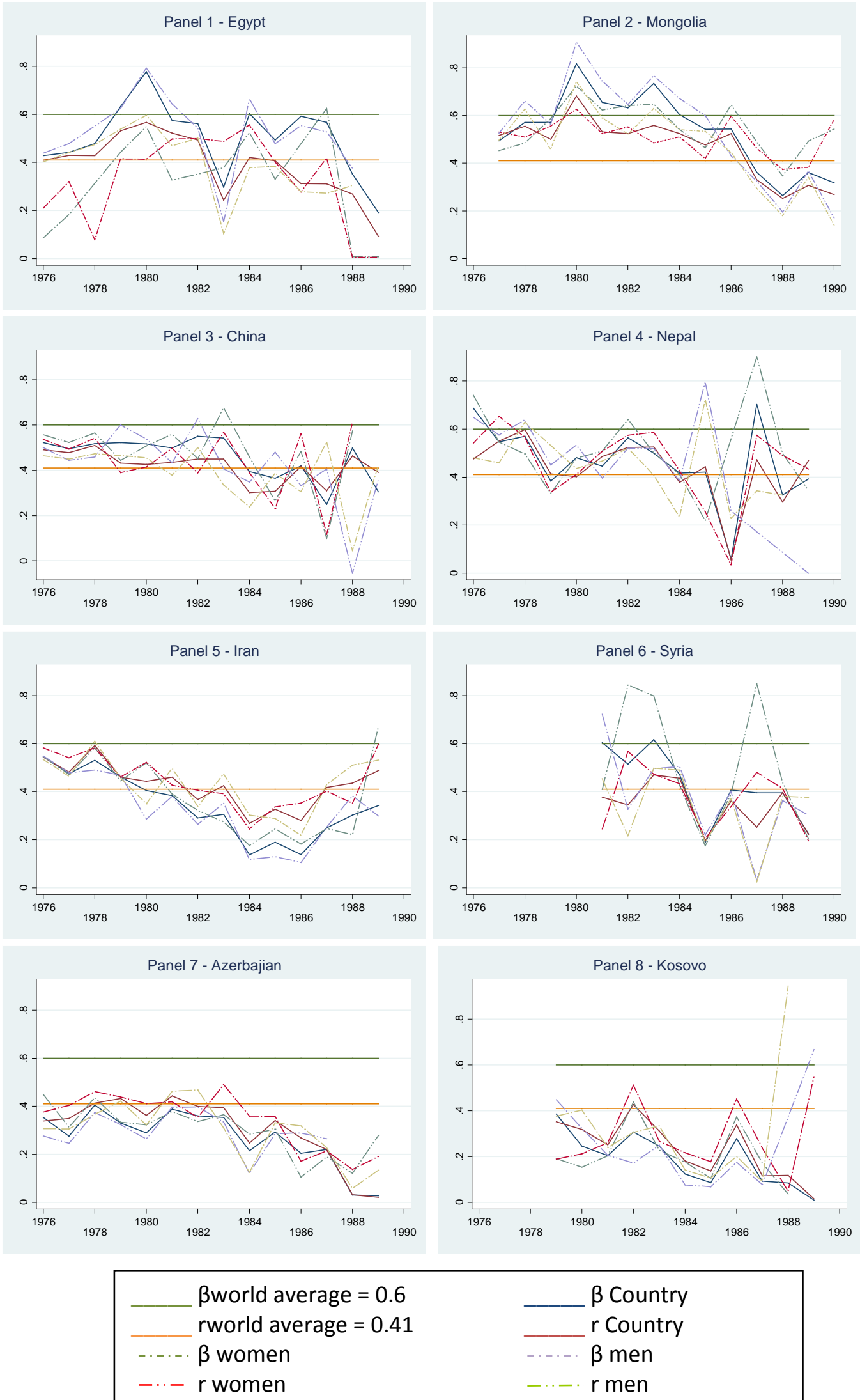
Figure 2: $B, r$ and sons' over parents' education

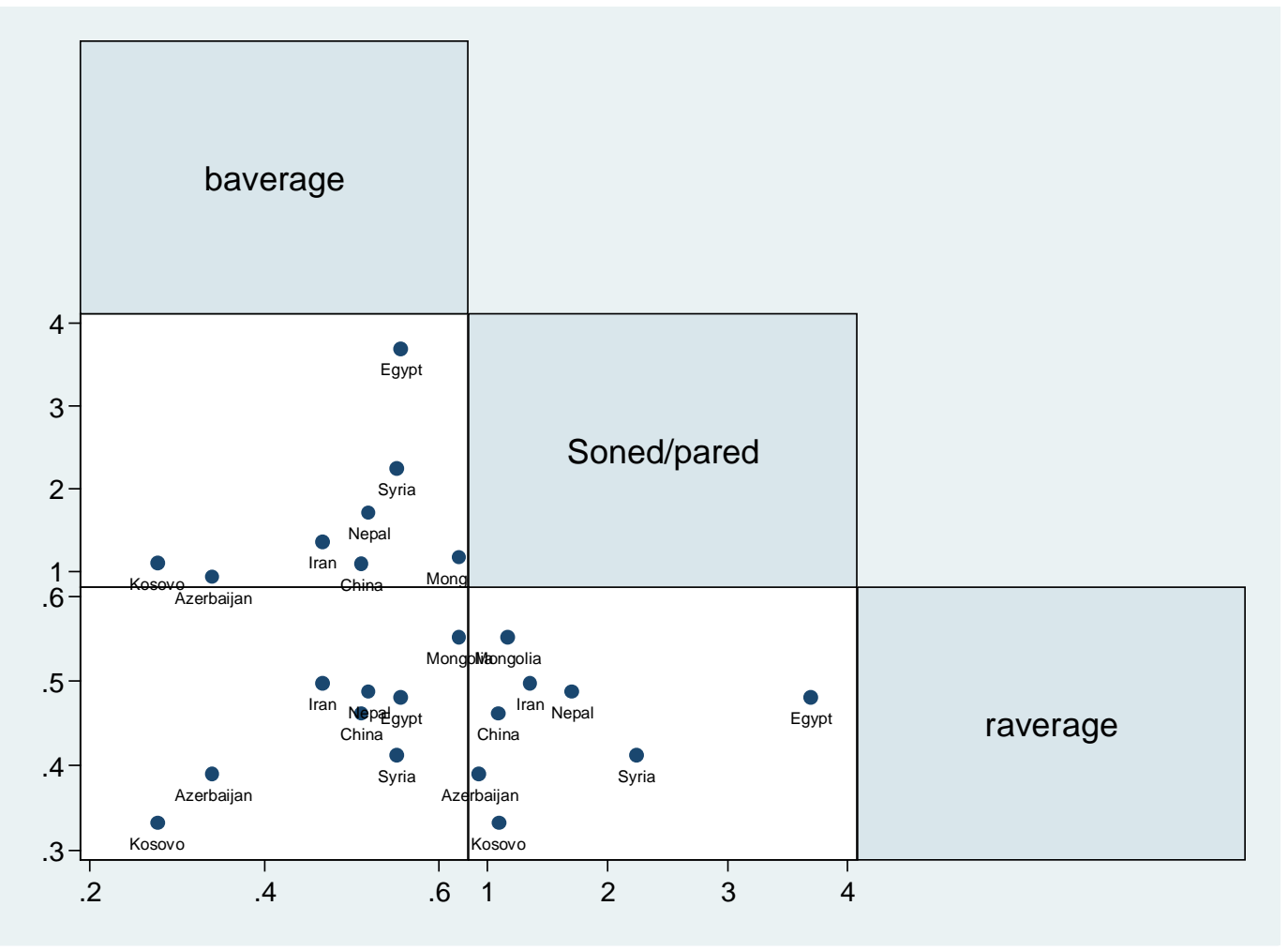

Note: The analysis is based on the over 24 years old for all countries, except Syria and Kosovo where we consider only the over 20 year old. 